\title{
Effects of regenerating forest cover on soil microbial communities: A case study in hilly red soil region, Southern China
}

\author{
H. Zheng, Z.Y. Ouyang * X.K. Wang, Z.G. Fang, T.Q. Zhao, H. Miao \\ Key Lab of Systems Ecology, Research Center for Eco-Environmental Sciences, \\ Chinese Academy of Sciences, Beijing 100085, China
}

Received 2 October 2003; received in revised form 9 June 2005; accepted 9 June 2005

\begin{abstract}
The stability and function of a soil ecosystem depends on the cycling of nutrients by the soil microbial community. To evaluate the effects of regenerating forest cover on the function of microbial community, the differences of four forest restoration approaches, including plantations of slash pine, Chinese fir, tea-oil camellia and natural secondary forest, in soil microbial community size, activity and metabolic diversity were measured by microbial biomass and metabolic diversity (BIOLOG) assays in a hilly red soil region, Southern China. Native soils were sampled and assessed with $0-20$ and $20-40 \mathrm{~cm}$ layers. Results showed that significant differences $(p<0.05)$ were found in soil microbial biomass among four forest restoration approaches. It was highest in the soil of natural secondary forest, medial in the plantations of tea-oil camellia and Chinese fir and the least in slash pine plantation. Principal component analysis (PCA) further revealed consistent differences of the metabolic diversity patterns in 0-20 cm soil, but not for Chinese fir plantation, tea-oil camellia plantation and natural secondary forest in $20-40 \mathrm{~cm}$ soil. Average well colour development (AWCD) and indices of richness and diversity showed significant difference in the four forest restoration approaches. The variable tendency of the indicators was the same as microbial biomass. These suggested that the ability to utilize sole-carbon-source and functional diversity (metabolic diversity) for soil microbial community were stronger in natural secondary forest than that in plantations. Altogether, microbial biomass and metabolic diversity patterns in 0 $20 \mathrm{~cm}$ soil of natural secondary forest were dominant, comparing with that of three plantations, viz. slash pine plantation, Chinese fir plantation and tea-oil camellia plantation. While in $20-40 \mathrm{~cm}$ soil there were no recognizable differences for above indicators among four vegetation types. Factors affecting the structure and function of soil microbial community appeared to be linked closely with artificial tending, soil and water loss, root biomass and litter production. The information gathered from the studies can be used to baseline data for forest restoration projects.
\end{abstract}

(C) 2005 Elsevier B.V. All rights reserved.

Keywords: Soil microbial community; Microbial biomass; Metabolic diversity patterns; BIOLOG; Forest restoration

\footnotetext{
* Corresponding author. Tel.: +86106284 9191; fax: +86 1062943822.

E-mail address: zyouyang@mail.rcees.ac.cn (Z.Y. Ouyang).
} 


\section{Introduction}

The stability and function of a soil ecosystem depends on the cycling of nutrients by the soil microbial community (Rogers and Tate, 2001). They are responsible for nitrogen fixation, nutrient cycling, immobilization of essential nutrients and production of phytohormones (Perry and Amaranthus, 1990; Turkington et al., 1988; Curl and Truelove, 1986). Forest ecosystems depend on the soil microbial community to convert nutrients from plant biomass and soil organic matter to mineral pools primarily used by plants (Rogers and Tate, 2001). Correspondingly, management strategies and restoration approaches significantly affected the structure and function of soil microbial communities (Bossio and Scow, 1995; Buyer and Drinkwater, 1997; Yang et al., 1998; Hu et al., 2002).

Commonly used indicators of the status and function of soil microbial communities include microbial community enumeration (microbial biomass) and metabolic diversity patterns (BIOLOG) (Rogers and Tate, 2001). Microbial biomass correlates with soil fertility and soil health (Powlson et al., 1987) and was recommended as a useful ecological indicator of stress caused by anthropogenic activities (Wardle, 1992). At the same time microbial biomass was also an important indicator of microbial community size, whereas BIOLOG was a method of analysing the potential metabolic diversity of soil microbial community (predominantly bacterial). Due to the redundancy of functions within soil microbial communities, microbial biomass would be insensitive to change in the microbial populations. As an important indicator for evaluating microbial community functional diversity, BIOLOG was more sensitive to changes in the functional microbial community than microbial biomass. BIOLOG has been widely used in assessing microbial metabolic diversity in agricultural soils under different management strategies (Bossio and Scow, 1995; Buyer and Drinkwater, 1997) and forest soil under different vegetations (Zak et al., 1994; Grayston et al., 1998). Over the years, increased understanding of the BIOLOG assay has demonstrated the reproducibility of BIOLOG profiles and supported the theory that shifts in BIOLOG metabolic diversity patterns are related to shifts in community composition (Haack et al., 1995).
Despite their ecological significance, the response of soil microbial communities to different forest restoration approaches is poorly understood. Mycorrhizae have been shown to be sensitive to anthropogenic disturbances (Zabinski and Gannon, 1997), but few data exist on microbial community structure and function response to anthropogenic activities (Zabinski and Gannon, 1997). The hilly red soil region of southern China covers the largest area $\left(2.18 \times 10^{6} \mathrm{~km}^{2}\right)$, including 10 provinces, possesses the highest reclamation index and is the most serious area of soil erosion in south of China. It was once known as "red desert of southern China". How to restore the degraded ecosystem is an important subject the area faced. The theoretical foundation was lacked for which forest restoration approach was the most feasible and propitious to improve soil fertility and restore the vegetation. The objective of this study was to assess the impact of different forest restoration approaches on the structure and function of soil microbial community in the hilly red soil region, Southern China and further to provide a fundamental for restoration practices.

\section{Materials and methods}

\subsection{Study site description}

The research was carried out at the Ecological Benefit Monitoring Station of the Yangtze River Protection Forest-the hilly red soil region of Southern Hunan Province, which is located in the small valley of Changchong village, Lanlong Country, Hengyang County of Hunan Province $\left(27^{\circ} 05^{\prime} \mathrm{N}, 112^{\circ} 18^{\prime} \mathrm{E}\right)$. The soil is red soil formed from the same parent material as arenaceous shale, which widely distributes in Southern China. In China Soil Taxonomy the soil is classified as fine loamy, hyperthermic, acidic, Udic Cambisols (Gong, 1999). The altitude ranges from 86 to $147 \mathrm{~m}$ above sea level. The average annual rainfall is about $1237 \mathrm{~mm}$ with the highest rainfall extending between May and August. The average annual temperature is $17.9^{\circ} \mathrm{C}$.

Representative types of man-made forests in Southern China are plantations of slash pine (Pinus elliottii), Chinese fir (Cunninghamia lanceolata) and tea-oil camellia (Camellia oleifera). In 1989, four 
restoration approaches were created after all the vegetation were cleared by the local people for firewood, expect for the tea-oil camellia trees which were planted in 1980. Before re-vegetation, the lands of plantations were shaped into horizontal belt.

(1) Slash pine plantation (SPP). It was periodically tended per 3-4 years. The way to tending is to loose the soil allover the ground and clear the grasses and shrubs in order to establish the pure forest of slash pine. The last tending was in 1998.

(2) Chinese fir plantation (CFP). It was periodically tended per 3-4 years. The way to tending is the same as that of SPP. The last tending was in 1998.

(3) Tea-oil camellia plantation (TCP). After reforestation, little management and disturbance have occurred.

(4) Natural secondary forest (NSF). The land has been closed for reforestation since 1989. There have been no disturbance in the area after protection. Now many conifers and hardwoods with prolific understory vegetation have established in the sampling site, such as $P$. elliottii, Pinus massoniana, Quercus aliena, Quercus fabri, Quercus glauca and others.

Before the plots were set, the soil condition was basically consistent (Yuan et al., 2003). For the study sites of four forest types, the slope is $18^{\circ}-25^{\circ}$. After forest cover regeneration, soil chemical properties under each forest type changed greatly (Table 1).

Each site had been divided into three replicate areas before the site was set in 1989. In July 2003, three composite soil samples were collected from three replicate areas of SPP, CFP, TCP and NSF to cover site heterogeneity. A composite sample is a mix of five individual samples $(25 \mathrm{~cm} \times 25 \mathrm{~cm})(0-20$ and 20 $40 \mathrm{~cm}$ depth) taken randomly $5-10 \mathrm{~m}$ apart in a replicate area, and kept in plastic bags on ice for transport to the laboratory. The soil samples were stored in the laboratory at $+4{ }^{\circ} \mathrm{C}$ and biological assays were conducted within $48 \mathrm{~h}$. All soil samples were sieved to pass $2 \mathrm{~mm}$ (Rogers and Tate, 2001). The residual soil was air-dried and analyzed for chemical properties.

\subsection{Soil chemical properties}

Soil $\mathrm{pH}$ was determined in 1:2.5 soil-water slurry using a combination glass electrode. Soil organic carbon (SOC) was determined by the oil bath$\mathrm{K}_{2} \mathrm{Cr}_{2} \mathrm{O}_{7}$ titration method. Total nitrogen (TN) was determined by the semi-micro Kjeldahl method. Available nitrogen (AN) was determined by a micro-diffusion technique after alkaline hydrolysis. Total phosphorus (TP) was determined colorimetrically after wet digestion with $\mathrm{H}_{2} \mathrm{SO}_{4}+\mathrm{HClO}_{4}$. Available phosphorus (AP) was exacted with $0.5 \mathrm{~mol} / \mathrm{l} \mathrm{NaHCO}_{3}$ solution ( $\mathrm{pH}$ 8.5). Phosphate-P in solution was determined colorimetrically by the formation of the blue phosphomolybdate complex following reduction with ascorbic acid. Total potassium (TK) was determined by the Cornfield method. Available potassium (AK) was determined by $\mathrm{CH}_{3} \mathrm{COONH}_{4}$ extraction method (Editorial Committee, 1996).

Table 1

Soil chemical properties of each experimental site

\begin{tabular}{lllllllll}
\hline Forest types & $\mathrm{pH}\left(\mathrm{H}_{2} \mathrm{O}\right)$ & $\mathrm{SOC}(\mathrm{g} / \mathrm{kg})$ & $\mathrm{TN}(\mathrm{g} / \mathrm{kg})$ & $\mathrm{TP}(\mathrm{g} / \mathrm{kg})$ & $\mathrm{TK}(\mathrm{g} / \mathrm{kg})$ & $\mathrm{AN}(\mathrm{mg} / \mathrm{kg})$ & $\mathrm{AP}(\mathrm{mg} / \mathrm{kg})$ & $\mathrm{AK}(\mathrm{mg} / \mathrm{kg})$ \\
\hline $0-20 \mathrm{~cm}$ & & & & & & & & \\
SPP & $4.22 \mathrm{c}$ & $8.01 \mathrm{c}$ & $0.54 \mathrm{c}$ & $0.15 \mathrm{ab}$ & $20.10 \mathrm{ab}$ & $41.00 \mathrm{c}$ & $0.53 \mathrm{bc}$ & $70.45 \mathrm{~b}$ \\
$\mathrm{CFP}$ & $4.37 \mathrm{~b}$ & $10.67 \mathrm{~b}$ & $0.73 \mathrm{~b}$ & $0.17 \mathrm{ab}$ & $15.97 \mathrm{c}$ & $62.33 \mathrm{~b}$ & $0.95 \mathrm{ab}$ & $77.03 \mathrm{~b}$ \\
$\mathrm{TCP}$ & $4.54 \mathrm{a}$ & $10.58 \mathrm{~b}$ & $0.74 \mathrm{~b}$ & $0.21 \mathrm{ab}$ & $22.17 \mathrm{a}$ & $64.00 \mathrm{~b}$ & $1.22 \mathrm{a}$ & $91.47 \mathrm{~b}$ \\
$\mathrm{NSF}$ & $4.42 \mathrm{~b}$ & $14.10 \mathrm{a}$ & $1.00 \mathrm{a}$ & $0.23 \mathrm{a}$ & $18.73 \mathrm{~b}$ & $84.67 \mathrm{a}$ & $0.83 \mathrm{~b}$ & $178.67 \mathrm{a}$ \\
& & & & & & & & \\
$20-40 \mathrm{~cm}$ & & & & & & & & \\
SPP & $4.31 \mathrm{~b}$ & $10.87 \mathrm{~b}$ & $0.45 \mathrm{~b}$ & $0.28 \mathrm{a}$ & $20.70 \mathrm{~b}$ & $35.33 \mathrm{~b}$ & $0.21 \mathrm{c}$ & $71.10 \mathrm{~b}$ \\
$\mathrm{CFP}$ & $4.28 \mathrm{~b}$ & $12.57 \mathrm{ab}$ & $0.58 \mathrm{ab}$ & $0.16 \mathrm{a}$ & $17.60 \mathrm{c}$ & $53.00 \mathrm{a}$ & $0.59 \mathrm{~b}$ & $59.77 \mathrm{~b}$ \\
TCP & $4.65 \mathrm{a}$ & $13.10 \mathrm{ab}$ & $0.61 \mathrm{a}$ & $0.25 \mathrm{a}$ & $23.53 \mathrm{a}$ & $55.00 \mathrm{a}$ & $0.93 \mathrm{a}$ & $74.17 \mathrm{ab}$ \\
$\mathrm{NSF}$ & $4.36 \mathrm{~b}$ & $14.67 \mathrm{a}$ & $0.69 \mathrm{a}$ & $0.18 \mathrm{a}$ & $20.70 \mathrm{~b}$ & $62.67 \mathrm{a}$ & $0.44 \mathrm{~b}$ & $98.00 \mathrm{a}$ \\
\hline
\end{tabular}

Values in same column followed by the same letter are not significantly different at $p<0.05$. 


\subsection{Microbial assays and root sampling}

Microbial biomass was determined by the chloroform fumigation method ( $\mathrm{Li}$ et al., 1996), using a $\mathrm{Kc}=0.45$. The metabolic diversity patterns were measured by using BIOLOG (Biolog Inc., Hayward, Calif.). Ten grams of soil was shaken 15 min with $95 \mathrm{ml}$ of sterile $0.145 \mathrm{M} \mathrm{NaCl}$ (Schutter and Dick, 2001). Soil samples were serially diluted to $10^{-3}$, and $125 \mu \mathrm{l}$ dilution was inoculated into each well of a GN-Biolog plate. Plates were incubated at $25^{\circ} \mathrm{C}$, and well absorbance values were read at $590 \mathrm{~nm}$ with a BIOLOG microplate reader at $4 \mathrm{~h}$ intervals after inoculation until $240 \mathrm{~h}$.

The average well colour development was calculated for each microplate. Although concerns for the use of this scaling technique exist (Howard, 1997), AWCD analysis allows a comparison of plates that have achieved the same degree of colour development regardless of differences in cell inoculum density that may cause differences in rates of colour development (Garland, 1996; Insam and Hitzl, 1999). A reference point of 0.6 AWCD was used to compare BIOLOG patterns.

Root sampling method was used as described in Dong (1996). Fifteen individual sample plots $(2 \mathrm{~m} \times 2 \mathrm{~m})$ were taken randomly under each forest types. Then all the roots were excavated and weighted in each sample plot. The roots were sampled in June, 2003.

\subsection{Statistical analyses}

Average well colour development was calculated according to Garland and Mills (1991), i.e., $\mathrm{AWCD}=\Sigma(C-R) / n$ where $C$ is colour production within each well (optical density measurement), $R$ is the absorbance value of the plate's control well, and $n$ is the number of substrates (GN plates, $n=95$ ). Biolog substrate richness and diversity were determined at each sampling point by ANOVA (SPSS, 10.0 Version). Richness refers to the total number of carbon sources utilized, and diversity was calculated as the Shannon index, where $\mathrm{H}^{\prime}=\Sigma(\mathrm{Pi} \times \ln (\mathrm{Pi}))$, and $\mathrm{Pi}$ is the value that the difference in optical density relative to the control well for each substrate divided by the total difference of the plate, i.e., $(C-R) / \Sigma(C-R)$. When significant $(\alpha=0.05)$ treatment differences were found, protected L.S.D. value was calculated to separate the mean.

The readings obtained from the selected BIOLOG microplates with 0.6 AWCD were further analysed and compared by principal component analysis (PCA). PCA is a statistical method used to reduce the number of variables to a smaller number of new variables called principal components (PCs). BIOLOG plates contain 95 substrates. Each of the individual 95 substrates was a variable and the mean of the triplicate plates was a sample. The plots of the PC scores for each sample were used to display differences in metabolic diversity patterns. Correlation analysis was used to relate the original variables (substrates) to the principal components. Interpretation of the principal components was based on significant factor loading of the individual substrates on each of the principal components (Rogers and Tate, 2001). ANOVA was performed on the coordinates of soil communities along principal components (PCs) 1 and 2. Protected L.S.D. values were calculated to separate community differences. In addition, correlation coefficients between substrates and PC coordinates were calculated to identify substrates whose slopes were represented by PCs 1 and 2 .

\section{Results}

\subsection{Microbial assays}

Differences of microbial biomass for soil microbial communities were significant between forest restoration approaches (Fig. 1). The microbial biomass declined insignificantly from upper $(0-20 \mathrm{~cm})$ to lower $(20-40 \mathrm{~cm})$ layer. ANOVA of these assays revealed forest-restored types effects on microbial biomass.

Microbial biomass ranged from $99.33 \mathrm{mg} \mathrm{C}$ for SPP $20-40 \mathrm{~cm}$ soils to $176.43 \mathrm{mg}$ C for NSF $0-20 \mathrm{~cm}$ soil. There were significant difference in microbial biomass of 0-20 cm soil between NSF and other forest types, but not between CFP and TCP (Fig. 1). Microbial biomass for SPP soil is the lowest and the differences between SPP and other forest types were significant. The trend in the $20-40 \mathrm{~cm}$ soil layer in microbial biomass was similar to that of $0-20 \mathrm{~cm}$ soil (Fig. 1). 


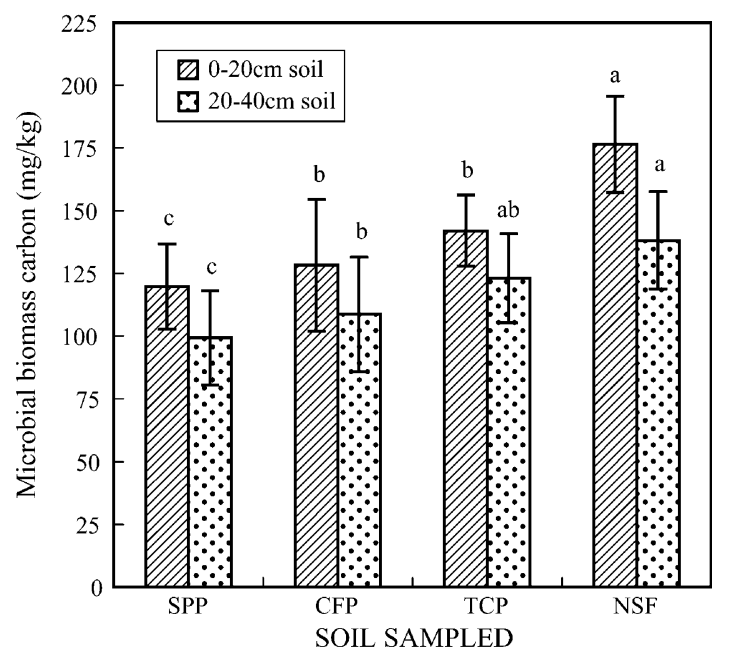

Fig. 1. Microbial biomass carbon in soils. Vertical lines represent \pm 1 standard deviation of the mean. Within each series, columns marked by the same letter are not significantly different at $p<0.05$.

\subsection{Metabolic diversity patterns}

Fig. 2 summarizes AWCD for microbial communities from the upper to lower layer of four vegetation types at $0-240 \mathrm{~h}$ after incubation. Microbial activity as measured by AWCD, continued to increase with time even at the later sampling points and was consistently higher for NSF sites than for other sites. But the

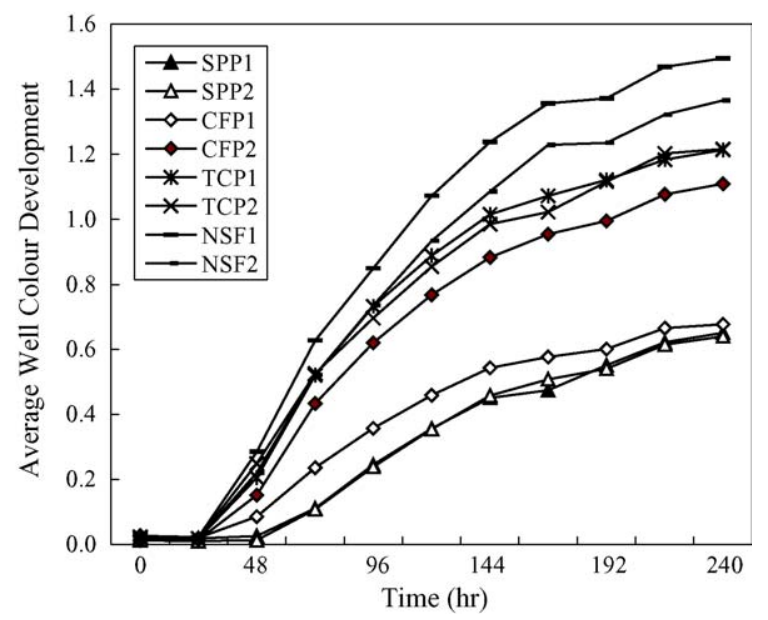

Fig. 2. Average well colour development (AWCD) in upper and lower layer soil. 1 and 2 represent the soil layer of $0-20$ and 20$40 \mathrm{~cm}$, respectively.
AWCD for SPP was consistently the lowest. There was evident difference between the upper and lower layer soil in NSF and CFP, but not in TCP and SPP. In addition, AWCD was an important indicator reflecting sole-carbon-source utilization ability. The values (AWCD) were ranked as following NSF $>$ TCP $>$ CFP $>$ SPP (Fig. 2). Analyses of metabolic diversity pattern were also done with 0.6 AWCD to maximize microbial population growth before interference from external sources affected absorbance measurements.

An overall PCA of the metabolic diversity patterns for upper layer $(0-20 \mathrm{~cm})$ soil was obtained by pooling the entire single-time-point data set from plates at the equivalent AWCD values of 0.6 (Fig. 3). Comparison of the metabolic diversity patterns of the soil microbial communities under four forest types provided information concerning the effect of widely differing forest on the soil microbial community. The PCA of $0-20 \mathrm{~cm}$ soil under CFP had the highest degree of variability (scattered data point) in their metabolic diversity patterns. This indicated the metabolic diversity patterns for the soil microbial community were variable. The results were mixed, with significant separation (treatment effects) occurring for four sampling sites. ANOVAs of the PC1 scores obtained from 0 to $20 \mathrm{~cm}$ soil of four sampling sites indicated the PC1 scores were significant different $\left(F_{3,8}=5.727 ; p<0.05\right)$. PC1 mainly sepa-

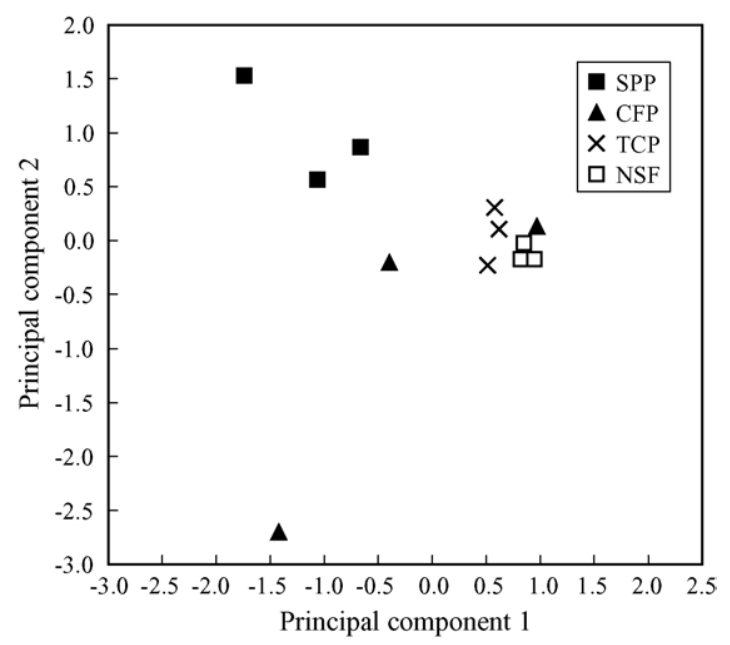

Fig. 3. Principal components analysis of carbon utilization profiles from upper $(0-20 \mathrm{~cm})$ layers soil. PC1 explains $19.6 \%$ of the variance of the data and $\mathrm{PC} 2$ explains $17.0 \%$ of the variance in the data. 
Table 2

Substrates with significant correlation coefficients for PC1 and PC2 in PCA of diversity patterns for each site of the upper layer (0-20 cm)

\begin{tabular}{|c|c|c|c|}
\hline $\mathrm{PC} 1$ & $r$ & $\mathrm{PC} 2$ & $r$ \\
\hline Carbohydrates & & Polymers & \\
\hline$\alpha$-D-Lactose & -0.758 & Glycogen & -0.855 \\
\hline Maltose & 0.734 & Tween 40 & -0.685 \\
\hline L-Rhamnose & -0.802 & Carbohydrates & \\
\hline Turanose & 0.866 & $N$-Acetyl-D-galactosamine & 0.582 \\
\hline Carboxylic acids & & D-Fructose & 0.846 \\
\hline Fromic acid & -0.855 & D-Mannitol & 0.775 \\
\hline D-Galacturonic acid & 0.805 & D-Melibiose & -0.76 \\
\hline D-Glucuronic acid & 0.584 & Methyl pyruvate & 0.854 \\
\hline$P$-Hydroxyphenylacetic acid & 0.594 & Mono-methyl succinate & -0.713 \\
\hline$\alpha$-Ketobutyric acid & -0.637 & Carboxylic acids & \\
\hline$\alpha$-Ketovaleric acid & -0.666 & cis-Aconitic acid & -0.598 \\
\hline Malonic acid & 0.917 & Propionic acid & 0.634 \\
\hline Quinic acid & 0.901 & Amino acids & \\
\hline Sebacic acid & -0.686 & Glycyl-L-glutamic acid & 0.729 \\
\hline Amino acids & & L-Histidine & 0.65 \\
\hline L-Alanine & 0.601 & Hydroxy-L-proline & -0.74 \\
\hline Amines/amides & & L-Ornithine & -0.719 \\
\hline Succinamic acid & -0.643 & L-Phenylalanine & -0.633 \\
\hline Putrescine & 0.719 & L-Proline & 0.823 \\
\hline 2-Aminoethanol & 0.693 & L-Serine & 0.694 \\
\hline Miscellaneous & & L-Threonine & 0.708 \\
\hline Urocanic acid & -0.607 & $\gamma$-Aminobutyric acid & 0.593 \\
\hline D, L- $\alpha$-Glycerol phosphate & 0.694 & & \\
\hline
\end{tabular}

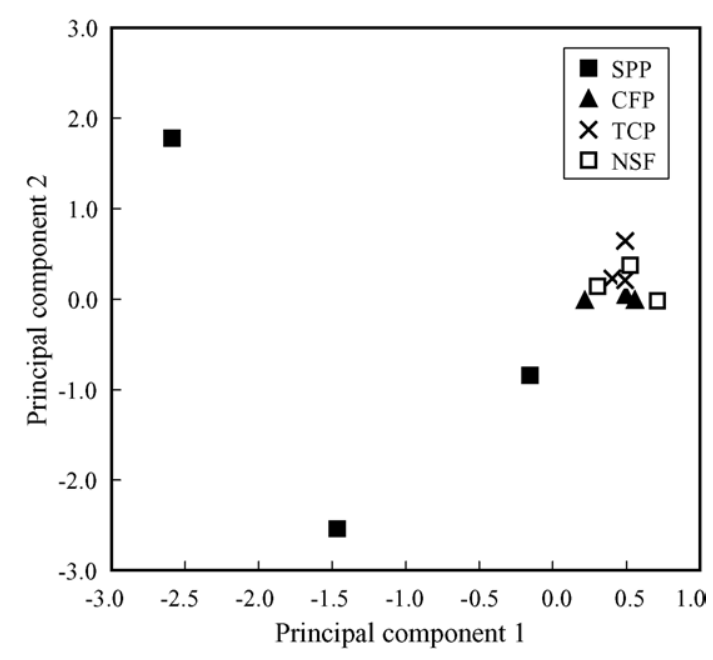

Fig. 4. Principal components analysis of carbon utilization profiles from upper $(20-40 \mathrm{~cm})$ layers soil. PC1 explains $26.4 \%$ of the variance of the data and PC2 explains $18.4 \%$ of the variance in the data. rates the NSF and TCP sites from the SPP site. ANOVAs of the PC2 scores indicated no significant difference existed in four sites.

Carbon sources with high correlation coefficients for PC1 and PC2 are listed in Table 2. Separation of the four sites along PC1 (Fig. 4) was significant affected by carboxylic acids (Table 2). Substrates affecting the PC2 were carbohydrate and amino acids (Table 2).

A comparison of the metabolic diversity patterns in the soil microbial community in $20-40 \mathrm{~cm}$ layer soil of four sites also showed a significant separation along PC1 $\left(F_{3,8}=4.496 ; p<0.05\right)$ and PC2 $\left(F_{3,8}=4.355\right.$; $p<0.05)$. And the ANOVAs result of PC1 was the same as that of PC2. There existed significant difference between SPP and other three sites, but not between CFP, TCP and NSF. Separation of the four sites along PC1 (Fig. 4) was significantly affected by carbohydrates and carboxylic acids (Table 3). Substrates affect the separation of PC2 were carbohydrates and amino acids (Table 3 ). 
Table 3

Substrates with significant correlation coefficients for PC1 and PC2 in PCA of diversity patterns for each site of the lower layer (20-40 cm)

\begin{tabular}{|c|c|c|c|}
\hline $\mathrm{PC} 1$ & $r$ & $\mathrm{PC} 2$ & $r$ \\
\hline Carbohydrates & & Polymers & \\
\hline Tween 80 & 0.632 & Tween 40 & 0.763 \\
\hline $\mathrm{N}$-Acetyl-D-galactosamine & -0.885 & Carbohydrates & \\
\hline L-Fucose & -0.605 & $\mathrm{~N}$-Acetyl-D-glucosamine & -0.694 \\
\hline$m$-Inositol & -0.796 & Adonitol & 0.686 \\
\hline$\alpha$-D-Lactose & -0.83 & D-Arabitol & -0.772 \\
\hline Maltose & 0.661 & D-Galactose & 0.711 \\
\hline D-Mannitol & 0.809 & $\alpha$-D-Glucose & -0.617 \\
\hline$\beta$-Methyl D-glucoside & -0.841 & Lactulose & -0.759 \\
\hline L-Rhamnose & -0.891 & D-Mannose & -0.954 \\
\hline D-Sorbitol & -0.793 & Mono-methyl succinate & 0.737 \\
\hline Sucrose & -0.798 & Carboxylic acids & \\
\hline D-Trehalose & 0.698 & Citric acid & -0.799 \\
\hline Methyl pyruvate & -0.873 & D-Galacturonic acid & -0.74 \\
\hline Carboxylic acids & & $\alpha$-Hydroxybutyric acid & 0.641 \\
\hline cis-Aconitic acid & 0.786 & $P$-Hydroxyphenylacetic acid & -0.872 \\
\hline D-Gluconic acid & -0.822 & Amino acids & \\
\hline D-Glucosaminic acid & 0.754 & L-Asparagine & -0.814 \\
\hline D-Glucuronic acid & 0.806 & L-Phenylalanine & 0.717 \\
\hline$\alpha$-Hydroxybutyric acid & -0.675 & L-Proline & 0.768 \\
\hline$\beta$-Hydroxybutyric acid & 0.729 & L-Pyroglutamic acid & -0.722 \\
\hline$\alpha$-Ketobutyric acid & -0.88 & L-Threonine & -0.886 \\
\hline D, L-Lactic acid & 0.727 & D, L-Carnitine & -0.771 \\
\hline Quinic acid & 0.854 & Miscellaneous & \\
\hline Sebacic acid & -0.753 & Uridine & -0.618 \\
\hline Amino acids & & Glucose-6-phosphate & 0.702 \\
\hline D-Alanine & 0.58 & & \\
\hline Hydroxy-L-proline & 0.73 & & \\
\hline L-Leucine & -0.883 & & \\
\hline L-Ornithine & -0.717 & & \\
\hline$\gamma$-Aminobutyric acid & -0.734 & & \\
\hline \multicolumn{4}{|l|}{ Amines/amides } \\
\hline Succinamic acid & -0.624 & & \\
\hline Putrescine & 0.777 & & \\
\hline 2-Aminoethanol & -0.885 & & \\
\hline \multicolumn{4}{|l|}{ Miscellaneous } \\
\hline 2, 3-Butanediol & 0.594 & & \\
\hline D, L- $\alpha$-Glycerol phosphate & 0.719 & & \\
\hline
\end{tabular}

Indices of substrate richness and diversity were calculated using the data set of 0.6 AWCD (Table 4). Substrate richness and diversity suggested how many sorts of carbon sources were utilized by the soil microbial communities in different forest regeneration types. The richness and diversity indices for NSF soil were the highest of four forest types. ANOVAs of richness and diversity indices indicated the NSF were significantly different from CFP and SPP in 0-20 cm soil. No significant differences were noted between TCP and NSF (Table 4). The difference in $20-40 \mathrm{~cm}$ soil was not distinct in four vegetation types, especially between CFP, TCP and NSF.

\section{Discussion}

\subsection{Experimental method of microbial assays}

Inoculum density was a major issue on how to interpret and what is the real value of BIOLOG as an assay of community function. It was noted that colour 
Table 4

Richness and diversity indices of utilized substrates for each site

\begin{tabular}{lll}
\hline Treatment & Richness & Diversity \\
\hline $0-20 \mathrm{~cm}$ soil & & \\
SPP & $49.000 \mathrm{c}$ & $3.735 \mathrm{~b}$ \\
CFP & $55.000 \mathrm{bc}$ & $3.786 \mathrm{~b}$ \\
TCP & $65.667 \mathrm{ab}$ & $4.022 \mathrm{ab}$ \\
NSF & $72.333 \mathrm{a}$ & $4.099 \mathrm{a}$ \\
$20-40 \mathrm{~cm}$ soil & & \\
SPP & $48.667 \mathrm{~b}$ & $3.680 \mathrm{~b}$ \\
CFP & $67.000 \mathrm{a}$ & $4.075 \mathrm{a}$ \\
TCP & $66.333 \mathrm{a}$ & $4.051 \mathrm{a}$ \\
NSF & $70.000 \mathrm{a}$ & $4.070 \mathrm{a}$ \\
\hline
\end{tabular}

Values in same column followed by the same letter are not significantly different at $p<0.05$.

development was correlated with cell density (Garland and Mills, 1991). To reduce the effects of differential rates of colour development (due to inoculum density) on the classification of samples there existed three methods to overcome the possible effects of inoculum density. Firstly, the data was transformed by dividing the raw difference (substrate well-control well value) of each well by the AWCD of the plate, giving greater indication of difference in sole-carbon-source utilisation patterns between samples (Garland and Mills, 1991). Although this method was still widely applied, its validity has been seriously questioned (Howard, 1997; Bossio and Scow, 1995). A second means of compensating for differences in inoculum density is to use a fix level of AWCD to determine the reading time for plate comparisons (Garland, 1996, 1997). This has mostly achieved by taking a series of readings across a prolonged incubation period, then selecting each plate reading closest to the reference AWCD (Garland et al., 2001). A third solution to remove the confounding effects of differing starting densities is to adjust inoculum concentration to similar values prior to inoculation (Zak et al., 1994; Garland, 1996, 1997). However, this is not a practical solution when comparing field sites, since this requires cell number counts or estimates of microbial to be done prior to the inoculation of the BIOLOG plates, delaying the process and allowing further alteration of the community structure during this time (PrestonMafham et al., 2002). Haack et al. (1995) also thought it was possible to achieve the structural and functional difference of microbial community only after the effects of inoculum concentration were removed. In our research the microbial biomass among the four sampling sites were very different (Fig. 1), but the second solution, i.e. using a fixed level of AWCD (0.6) to determine the reading times for plates comparisons through taking multiple time point readings (at 4-h interval), was used to overcome the difference of inoculum density. Therefore the results could reflect the structural and functional difference of soil microbial communities in different sampling sites.

\subsection{Effects of regenerating forest cover on soil microbial communities}

Microbial biomass correlated nearly with soil fertility and health and was recommended as a useful ecological indicator of stress caused by anthropogenic activities (Wardle, 1992). And microbial biomass reflected the size of soil microbial community. While average well colour development (AWCD) and functional diversity indices reflected their activity and functional diversity. Concretely speaking, AWCD reflects the sole-carbon-source utilization ability of soil microbial community and it was also an important indicator reflecting microbial activity (Zabinski and Gannon, 1997), and the indices of substrates richness and diversity reflected the number of utilized carbon source patterns, viz. functional diversity (metabolic diversity), based on consistent average well colour development (AWCD). The structure and function of different microbial communities was compared by microbial biomass carbon and BIOLOG assay in this study. Both the microbial biomass carbon reflecting the size of soil microbial community and the AWCD, functional diversity indices reflecting the activity and functional diversity were dominant in NSF, comparing with three plantations (Figs. 1 and 2, Table 4). Based on the consistent soil situation in four forest types, different restoration approaches and management strategies resulted in the difference of structure and function for soil microbial community. That is to say, artificial reforestation not only reduced microbial biomass carbon (Fig. 1), but also decreased microbial populations that could utilize certain sorts of carbon sources (expressed by richness index, Table 4) and the ability to utilize single-carbon-source for microbial community (expressed by AWCD), comparing with NSF. Natural restoration was more propitious to improve the structure and function of soil microbial 
community, especially in $0-20 \mathrm{~cm}$ layer. Reasons for stronger structure and function of microbial communities in NSF soil could be as following.

Firstly, improper artificial tending may be one of the main reasons for decreasing soil organic matter, which was one of the utilized carbon sources of soil microbial community. On the one hand, loosening the soils all over the ground breaks up macroaggregates and exposes previously protected organic matter in soil macroaggregates during artificial tending, including land shaping; on the other hand, it accelerated the mixture between organic residual and soils. Thus, soil organic carbon of plantation has less physical protection than that of NSF. Due to the mixture of organic residual and soil and enhanced microbial activity, part of the organic matter was decomposed. Lower organic carbon content in plantation soils may also partly result from periodically tending and land shaping, compared with NSF soil (Table 1). However, decrease in carbon source availability will reduce the diversity of soil microbial community accordingly (Tables 1 and 4). Consequently in the early stage of forest restoration, altering the above method of artificial tending may be more effective to protect soil, such as loosening the soils around the basal of the trees instead of loosening the soils all over the ground.

Secondly, more serious soil and water loss lead to the decrease of soil organic carbon that was one of the utilized carbon source of soil microbial community and the deterioration of habitation for soil microbial community in plantations. Based on 5-year observation, Tian et al. (2002) reported that in four vegetation types the severe degree of soil and water loss was ranked as follows: SPP $>$ CFP $>$ TCP $>$ NSF. The effect of controlling soil and water loss was the most obvious in NSF. In plantations, lower soil organic carbon may partly due to more severe soil and water loss (Table 1). The loss of this carbon source would also decrease the amount and sort of soil microbes, as was reflected by the indicators of microbial biomass carbon, utilized substrate richness and Shannon's diversity indices (Fig. 1, Table 4).

Thirdly, root biomass and litter production may be one of important factors affecting soil microbial communities. Roots themselves and plant root exudates were both the carbon source of soil microbial communities (Campell et al., 1997). In response to larger root biomass, the structure and function of soil

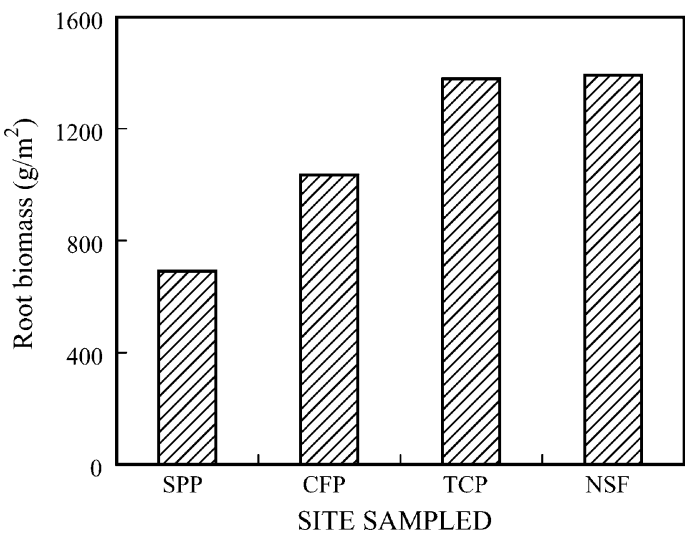

Fig. 5. Root biomass for each site.

microbial community were enhanced in NSF and TCP (Figs. 1, 2 and 5, Table 4). Differences in soil microbial community may also due to changes in organic matter availability due to litter decomposition (Aber et al., 1990). Its enhanced structure and function of soil microbial communities under TCP and NSF probably relates to higher quality litter fall and higher litter fall production (Fig. 6). Yuan et al. (2003) reported that in TCP and NSF above $70 \%$ of the total leaf litter fall was easily decomposed broad leaf. However, in SPP and CFP $82.90 \%$ and $69.95 \%$ of the total leaf litter fall were hard-decomposed needle leaf of slash pine and Chinese fir respectively (Fig. 6) (Yuan et al., 2003). The needles have been found to

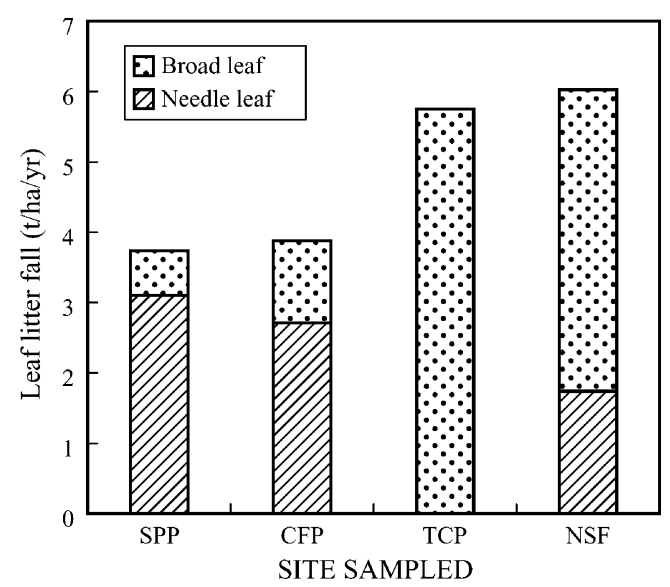

Fig. 6. Annual litter fall amount and their composition under forest types. 
degrade at different rate than deciduous leaf litter due to their high lignin content (Yu and Peng, 1996).

Finally, soil microbial community also are responsible for nitrogen fixation, nutrient cycling, immobilization of essential nutrients, and production of phytohormones (Perry and Amaranthus, 1990; Turkington et al., 1988; Curl and Truelove, 1986). Soil organic carbon, total nitrogen, total phosphorus, available nitrogen and available potassium possess the highest value in NSF soils, especially in $0-20 \mathrm{~cm}$ layer soils (Table 1), as may be in relation to stronger structure and function of microbial community in NSF soil. Accordingly, higher soil fertility is also propitious to improve the habitation of soil microbial community and provide richer carbon source for soil microbial community.

It is noticeable that for the structure and function of soil microbial community, not only the microbial biomass and AWCD but also the diversity indices of microbial communities in SPP soils are significant lower than that of other forest soils. And in the study slash pine is exotic species. Do there exist interactions between exotic species and soil microbial community. If there exist, how exotic species influence the structure and function of soil microbial communities is an important issue need to further explored in order to protected healthy soil ecosystem.

\section{Guidelines for restoration}

The results showed that natural restoration was more propitious to improve the structure and function of soil microbial communities, comparing with artificial reforestation. This field study provides baseline data for forest ecosystem restoration and management in hilly red soil region, Southern China. In addition, BIOLOG assays evidently distinguished the difference of different microbial communities and it was a good method to assess functional diversity of soil microbial community.

\section{Acknowledgements}

We acknowledge the financial supporting of the National Key Basic Research Program (G2000046807), the National Natural Science Foun- dation of China (30230090) and Innovation Group Project of National Natural Science Foundation of China (No. 40321101). We also thank Prof. Z.K. Yuan, Prof. X.Q. Li and D.L. Jiang for help in experimental investigation and sampling.

\section{References}

Aber, J.D., Melillo, J.M., McClaugherty, C.A., 1990. Predicting long-term patterns of mass loss, nitrogen dynamics, and soil organic matter formation from initial fine litter chemistry in temperate forest ecosystems. Can. J. Bot. 68, 22012208.

Bossio, D.A., Scow, K.M., 1995. Impact of carbon and flooding on the metabolic diversity of microbial communities in soils. Appl. Environ. Microbiol. 61, 4043-4050.

Buyer, J.S., Drinkwater, L.E., 1997. Comparison of substrate utilization assay and fatty acid analysis of soil microbial communities. J. Microbiol. Methods 30, 3-11.

Campell, C.D., Grayston, S.J., Hirst, D.J., 1997. Use of rhizosphere sources in sole carbon source tests to discriminate soil microbial communities. J. Microbial Methods 30, 33-41.

Curl, E.A., Truelove, B., 1986. The Rhizosphere. Springer-Verlag, Berlin, pp. 288.

Dong, M., 1996. Standard methods for observation and analysis in Chinese ecosystem research netwook: Survey, observation and analysis of terrestrial biocommunities, 129-135. Standards Press of China, Beijing, pp. 70-71 (in Chinese).

Editorial Committee, 1996. Soil Physical and Chemical Analysis and Description of Soil Profiles. Standards Press of China, Beijing (in Chinese).

Garland, J.L., 1996. Analytical approaches to the characterisation of sample microbial communities using patterns of potential $\mathrm{C}$ source utilisation. Soil Biol. Biochem. 28, 213-221.

Garland, J.L., 1997. Analysis and interpretation of community-level physiological profiles in microbial ecology. FEMS Microbial Ecol. 24, 289-300.

Garland, J.L., Mills, A.L., 1991. Classification and characterization of heterotrophic microbial communities on the basis of patterns of community-level sole-carbon-source utilization. Appl. Environ. Microbiol. 57, 2351-2359.

Garland, J.L., Mills, A.L., Young, J.S., 2001. Relative effectiveness of kinetic analysis vs single point readings for classifying environmental samples based on community-level physiological profiles (CLPP). Soil Biol. Biochem. 33, 1059-1066.

Gong, Z.T. (Ed.), 1999. Chinese Soil Taxonomy. Science Press, Beijing, (in Chinese), p. 676.

Grayston, S.J., Wang, S., Campbell, C.D., Edwards, A.C., 1998. Selective influence of plant species on microbial diversity in the rhizosphere. Soil Biol. Biochem. 30, 369-378.

Haack, S.K., Garchow, H.M., Klug, J., Forney, L.J., 1995. Analysis of factors affecting the accuracy, reproducibility, and interpretation of microbial community carbon source utilization patterns. Appl. Environ. Microbiol. 61, 1458-1468. 
Howard, P.J.A., 1997. Analysis of data from BIOLOG plates: comments on the method of Garland and Mills. Soil Biol. Biochem. 29, 1755-1757.

Hu, B., Duan, C.Q., Wang, Z.H., Zhang, S.B., Qi, L.Q., 2002. Effect of vegetation rehabilitation measures on soil fertility and soil enzymatic activity in degraded ecosystem. Acta Pedologica Sin. 39 (4), 604-608 (in Chinese).

Insam, H., Hitzl, W., 1999. Data evaluation of community-level physiological profiles: a reply to letter of P J. A. Howard. Soil Biol. Biochem. 31, 1198-1200.

Li, F.D., Yu, Z.N., He, S.J. (Eds.), 1996. Agricultural Microbiology Experimental Technique. Publishing House of Chinese Agriculture, Beijing, (in Chinese), pp. 82-83.

Perry, D., Amaranthus, M., 1990. The plant-soil bootstrap: microorganisms and reclamation of degraded ecosystems. In: Berger, J. (Ed.), Environmental Restoration: Science and Strategies for Restoring the Earth. Island Press, Washington, DC, pp. 94-102.

Powlson, D.S., Brookes, P.C., Christensen, B.T., 1987. Measurement of soil microbial biomass provides an early indication of changes in total soil organic matter due to straw incorporation. Soil Biol. Biochem. 19, 159-164.

Preston-Mafham, J., Boddy, L., Randerson, P.F., 2002. Analysis of microbial community functional diversity using sole-carbonsource utilization profiles-a critique. FEMS Microbiol. Ecol. 42, 1-14.

Rogers, B.F., Tate III, R.L., 2001. Temporal analysis of the soil microbial community along a toposequence in Pineland soils. Soil Biol. Biochem. 33, 1389-1401.

Schutter, M., Dick, R., 2001. Shift in substrate utilization potential and structure of soil microbial communities in response to carbon substrates. Soil Biol. Biochem. 33, 1481-1491.
Tian, Y.X., Li, X.Q., Yuan, Z.K., He, Y.J., Chen, X.P., Ni, A.P., 2002. Studies on benefit of soil and water conservation of different forest types in red soil regions of South Hunan. Res. Soil Water Conserv. 9 (4), 80-82 (in Chinese).

Turkington, R., Holl, F.B., Chanway, C.P., Thompson, J.D., 1988. The influence of microorganisms, particularly Rhizobium, on plant competition in grass-legume communities. In: Davy, A.J., Hutchings, M.J., Watkinson, A.R. (Eds.), Plant Population Ecology. Blackwell Scientific Publications, Oxford UK, pp. 343-366.

Wardle, D.A., 1992. A comparative assessment of factors which influence microbial biomass carbon and nitrogen levels in soil. Biol. Rev. 67, 321-358.

Yang, Y.S., He, Z.M., Lin, G.Y., 1998. Effect of different improving patterns on fertility of severely degraded granitic red soil. Acta Pedologica Sin. 35 (2), 276-282 (in Chinese).

Yu, Z.Y., Peng, S.L., 1996. The Study on Restoration Ecology of Degraded Ecosystems in Tropical and Sub-tropical Region. Guangdong Science and Technology Press, Guangzhou, pp. 185-191 (in Chinese).

Yuan, Z.K., Lang, N.J., Wu, Q.X., 2003. Configured Techniques of Protection Forests System Construction in Altiplano and Hilly Region of Yangze River Mid-low Reaches-Study and Demonstration. Hunan Science and Technology Press, Changsha, pp. 131-133 (in Chinese).

Zabinski, C.A., Gannon, J.E., 1997. Effects of recreational impacts on soil microbial communities. Environ. Manag. 21 (2), 233238.

Zak, J.C., Willing, M.R., Moorhead, D.L., Wildman, H.G., 1994. Functional diversity of microbial communities: a quantitative approach. Soil Biol. Biochem. 26, 1101-1108. 